\title{
PENGEMBANGAN MATHLET MATEMATIKA EKSPLORATIF UNTUK MENINGKATKAN KOMPETENSI MATEMATIKA SISWA SMP KELAS VIII DI SINGARAJA
}

\author{
Gede Suweken \\ Jurusan Pendidikan Matematika, Fakultas MIPA, Universitas Pendidikan Ganesha, \\ Singaraja, Indonesia \\ e-mail: gdsuweken5@gmail.com
}

\begin{abstract}
Abstrak
Penelitian ini adalah penelitian pengembangan yang dimaksudkan untuk meningkatkan kompetensi siswa kelas VIII terhadap konsep-konsep matematika. Pada tahun pertama, beberapa mathlet berhasil dibuat. Mathlet-mathlet tersebut juga telah divalidasi oleh beberapa orang yang kompeten di bidangnya dan juga telah mengalami validasi empirik yang sifatnya terbatas. Pada tahun kedua penelitian dilanjutkan dengan melakukan eksperimen untuk mengetahui pengaruh integrasi mathlet dalam pembelajaran terhadap prestasi belajar matematika siswa kelas VIII di Singaraja. Empat buah SMP (3 SMPN dan 1 SMP Swasta) dengan 240 orang siswa telah dipilih secara random untuk menjadi sampel penelitian. Hasil penelitian menunjukkan bahwa integrasi mathlet ke dalam pembelajaran matematika berpengaruh positif terhadap prestasi belajar siswa dengan $\mathrm{F}=$ 23,33 melawan $F=3,89$ untuk taraf signifikansi $95 \%$. Pengaruh ini bersifat umum tidak bergantung pada tingkat kemampuan siswa. Hal ini terbukti dari tidak adanya interaksi antara Integrasi Mathlet dan tingkat kemampuan siswa terhadap prestasi belajar matematika. Berdasarkan pada hasil penelitian yang diperoleh, peneliti menyarankan agar para guru menggunakan mathlet dalam pembelajaran matematika mereka untuk meningkatkan kualitas pembelajaran yang dilaksanakan.
\end{abstract}

Kata kunci: pembelajaran matematika berkualitas, media pembelajaran eksploratif, mathlet, prestasi belajar, pengaruh positif, pengaruh interaktif.

\begin{abstract}
This research is a developmental research which is caried out in order to improve students' competencies toward mathematical concepts. In the first year, some mathleths have been built. Those mathleths are also have been validated by expert judgement and by a limited number of students. In the second year the research is continued to answer a single question, that is "whether or not the integration of those mathlets in mathematucs learning will improve students achievement." To answer this question 4 SMP consisted of 240 students of grade VIII have been choosen randomly to become the reserach sample. Research results show that the integration of mathlets in mathematics learning is indeed improve students achiement with $F=23.33$ versus $F=3.89$ for level significancy $95 \%$. In fact this positive impact is true in general since there is no interaction effect between the integration of mathlet and students' level of capability toward the mathematics achievement. Based on these findings we propose that teachers use mathlet during their mathematics teaching, since mathlets will improve the teaching quality.
\end{abstract}

Keywords: qualified mathematics learning, explorative media, mathlet, students' achievement, positive effect, interactive effect. 


\section{PENDAHULUAN}

Telah disadari bahwa matematika adalah landasan dan alat bagi pemahaman dan pengembangan ilmu pengetahuan dan teknologi (iptek). Posisi matematika yang penting ini diperoleh berkat karakteristiknya yang sangat sesuai dengan karakteristik iptek itu sendiri. Karena itu, untuk mengantisipasi perkembangan iptek yang semakin pesat, karakteristik matematika harus dikuasai siswa dengan baik. Karakteristik penting dari matematika adalah:

Matematika sebagai kegiatan penelusuran pola dan hubungan, (2) matematika sebagai kreativitas yang memerlukan imajinasi, intuisi, dan penemuan, (3) matematika sebagai kegiatan pemecahan masalah, dan (4) matematika sebagai alat berkomunikasi. (Depdiknas, 2004).

Namun, harapan Depdiknas (yang pada hakekatnya juga merupakan harapan orang yang mengerti Matematika, Sains dan Teknologi) tentang karakteristik matematika yang harus dikusasi siswa, masih belum diikuti oleh proses pembelajaran yang mengarah pada penguasaan karakteristikkarakteristik tersebut. Pengamatan selama membimbing mahasiswa PPL baik di SD, SMP, maupun SMA, menunjukkan bahwa masih banyak guru yang mengajarkan matematika hanya sebagai kumpulan rumus, prosedur, atau algoritma, yang sifatnya hapalan, dengan sumber belajar yang hanya berupa buku teks. Proses pemaknaan konsep, keterkaitan antar konsep, berbagai cara merepresentasikan konsep, dan berbagai karakteristik matematika yang lain, adalah hal-hal penting yang belum tersentuh dalam pembelajaran. Praktek-praktek pembelajaran yang tidak kreatif seperti ini akan semakin menjauhkan siswa dari karakteristik matematika yang sebenarnya, memberikan citra yang keliru tentang matematika itu sendiri, dan menjadikan matematika sebagai bidang studi yang membosankan, tidak menarik, hapalan, dan tak bermakna karena abstrak dan tercabut dari realitas kehidupan. Jika kondisi ini terus berlanjut, maka dimasa datang kita akan semakin jauh tertinggal dalam penguasaan dan pengembangan iptek, karena kurangnya sumber daya manusia dengan tingkat penguasaan matematika (alat iptek) yang memadai.

Salah satu upaya yang bisa dilakukan untuk meningkatkan kualitas pembelajaran matematika yang kualitasnya belum memuaskan tersebut adalah dengan mengintegrasikan mathlet (mathematical applet) dalam pembelajaran matematika. Yang dimaksud dengan mathlet dalam penelitian ini adalah program komputer yang tidak terlalu besar (sehingga juga tidak terlalu kompleks) yang fungsinya sebagai media dimana siswa bisa melakukan eksplorasi terhadap konsep-konsep matematika yang dipelajari. Applet umumnya dibuat dengan menggunakan Java, namun kini applet juga bisa dibuat dengan menggunakan Excel, Maple, Geonext, Geogebra, Geometer Sketchpad, Cabri, CAR, dan lain-lain.

Mengapa pembelajaran matematika eksploratif berbantuan mathlet bisa memenuhi harapan kurikulum seperti yang telah dituliskan di atas?

Hal in disebabkan karena mathlet memungkinkan konsep-konsep matematika disajikan tidak dalam bentuk jadi, melainkan sebagai suatu fenomena dimana siswa terlebih dahulu diarahkan untuk melakukan eksplorasi, sebelum pada akhirnya mereka sampai pada rumus abstrak yang pada dasarnya hanyalah ringkasan akhir dari 
keseluruhan proses dan konsep yang sedang dipelajari. Mathlet dengan mudah didisain agar bersifat multi-representatif dengan cara menampilkan suatu konsep matematika sekaligus dalam bentuk aljabar, numerik, dan grafis. Dengan cara seperti ini, konsep-konsep matematika yang dipelajari akan menjadi lebih kaya representasi, lebih intuitif, lebih jelas saling keterkaitannya, lebih bermakna, dan lebih sesuai dengan harapan kurikulum.

Pandangan yang telah dipaparkan di atas tidak hanya bersifat teoritis, namun didukung oleh beberapa hasil penelitian. Beberapa penelitian tindakan kelas (PTK) tentang pemanfaatan komputer dalam pembelajaran matematika telah sempat penulis lakukan, baik itu di tingkat SMP, SMA, maupun perguruan tinggi (Suweken; 2008, 2007, 2006). Hasil yang paling mengesankan dari PTK yang telah dilakukan tersebut adalah bahwa keterlibatan siswa/mahasiswa dalam pembelajaran benar-benar sangat positif, atmosfir kelas ketika itu benar-benar atmosfir belajar, diskusi siswa di depan komputer dengan mathletnya benar-benar diskusi tentang matematika.

Namun demikian, dalam berbagai PTK yang telah dilakukan tersebut peneliti masih terlalu dominan. Guru belum dilibatkan dalam proses pembuatan mathlet dan LKS serta rancangan pembelajarannya. PTK yang sudah dilakukan masih bersifat sangan terbatas, baik dari segi materi yang dicakup maupun dari segi besar subjek penelitian. Karena itu, tentu saja hasil-hasil yang diperoleh lewat PTK belum bisa digeneralisasi ke subjek yang lebih luas. PTK yang telah dilakukan tersebut, juga belum menghasilkan pengetahuan tentang cara yang efektif dan efisien dalam mengintegrasikan mathlet dalam pembelajaran matematika. Hasil-hasil penelitian yang sudah dilakukan menunjukkan bahwa masih belum ada pengetahuan yang konsklusif tentang cara terbaik dalam mengintegrasikan mathlet dalam pembelajaran. Beberapa penelitian menunjukkan bahwa pembelajaran matematika dimana siswa melakukan eksplorasi langsung terhadap mathlet yang disediakan berhasil meningkatkan hasil belajar secara signifikan. (Schwingendorf, Keith E., et.al., 2000). Sementara pada penelitian yang lain justru sebaliknya yang terjadi Gadanidis, George, 2000). Dalam kasus yang kedua, siswa yang dalam pembelajarannya langsung melakukan eksplorasi pada mathlet, ternyata memperoleh hasil belajar yang lebih rendah dibandingkan dari siswa yang diberikan orientasi terlebih dahulu sebelum melakukan eksplorasi. Ada kecendrungan bahwa siswa yang langsung disuruh melakukan eksplorasi, menghadapi eksplorasi tersebut sebagai permainan (game), bukan sebagai bahan pelajaran yang tujuannya untuk membantu siswa memahami konsep-konsep matematika. Dalam kaitannya dengan ini, kemungkinan besar cara mengintegrasikan mathlet dalam pembelajaran berinteraksi dengan tingkat kemampuan siswa dalam memberikan pengaruh terhadap hasil belajar.

Pada tahun pertama, penelitian ini difokuskan untuk meningkatkan pengetahuan guru akan pentingnya media pembelajaran eksploratif dalam pembelajaran. Disamping itu, penelitian juga difokuskan untuk meningkatkan keterampilan guru dalam membuat media pembelajaran matematika yang eksploratif (mathlet). Mathlet-mathlet yang dihasilkan pada tahun pertama telah divalidasi oleh orang-orang yang ahli di bidangnya dan juga 
telah divalidasi secara empirik melalui beberapa eksperimen terbatas.

\section{Rumusan Masalah}

dilanjutkan untuk

Pada tahun kedua penelitian

1) Apakah ada perbedaan hasil belajar antara siswa yang pembelajaran matematikanya berlangsung lewat eksplorasi mathlet dengan siswa yang pembelajarannya berlangsung secara konvensional, dan

2) Apakah ada pengaruh interaktif antara tingkat kemampuan siswa dan pembelajaran matematika eksploratif berbantuan mathlet terhadap hasil belajar siswa, melalui penelitian pada beberapa SMP di Singaraja.

\section{METODE PENELITIAN}

\section{Disain Penelitian}

Penelitian ini dirancang dalam dua tahun dan didisain mengikuti alur pemikiran penelitian pengembangan seperti yang terlihat pada diagram dibawah ini. Diagram tersebut diadaptasi dari model pengembangan perangkat pembelajaran 4-d (define, design, develop, and disseminate) oleh Thiagaraja, et. al. (1974). Pada tahun pertama dari penelitian ini, mathlet dan LKS yang akan digunakan dalam penelitian tahun ke dua mulai dikembangkan. Proses pengembangannya mengikuti desain sebagai berikut: 


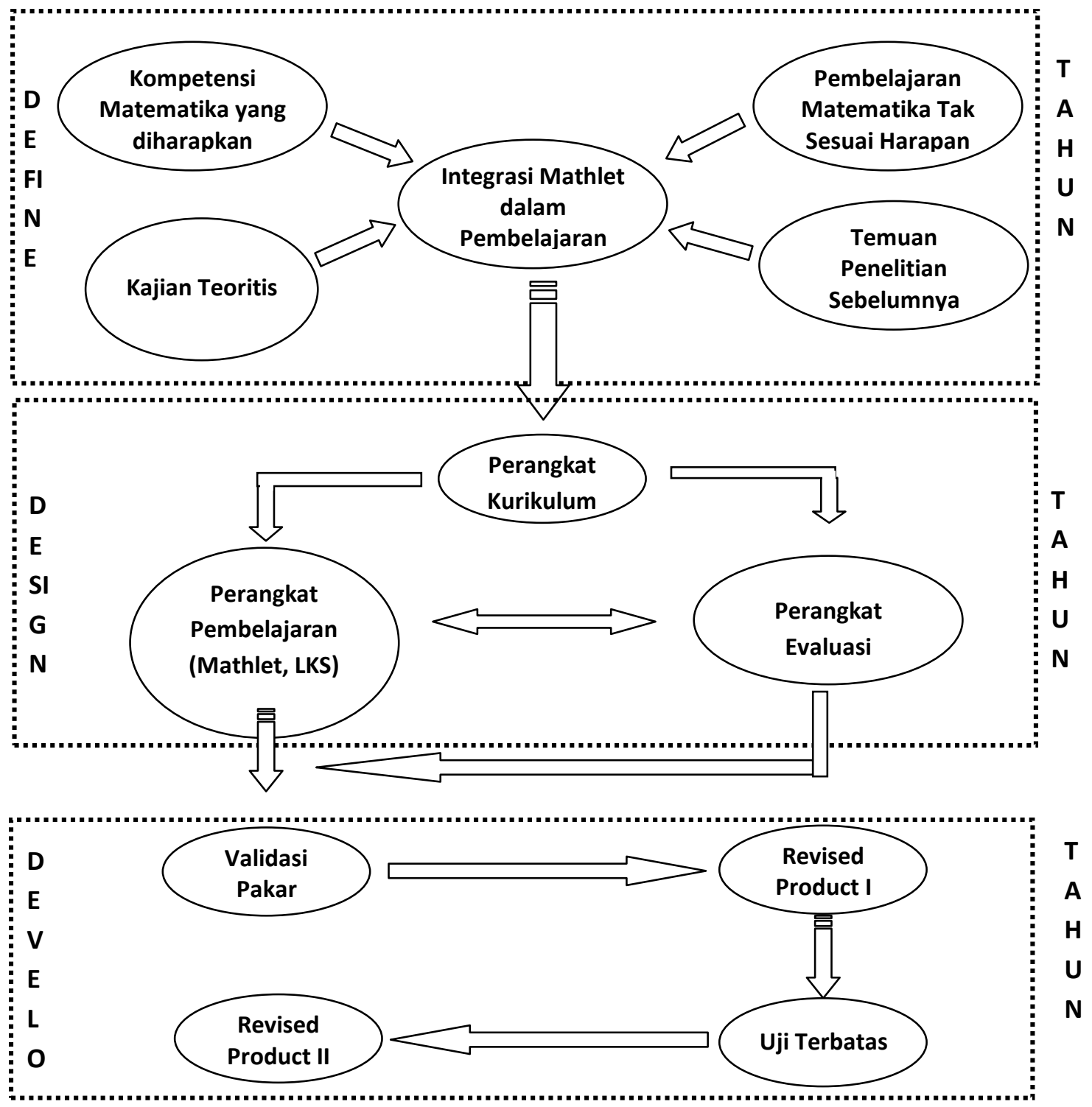

Gambar 1: Desain pengembangan mathlet beserta LKS-nya. 
Pada tahun kedua mathlet-mathlet yang telah dihasilkan pada tahun pertama digunakan dalam suatu eksperimen untuk mengetahui pengaruhnya terhadap prestasi belajar siswa. Adapun disain eksperimen yang digunakan dalam penelitian ini adalah sebagai berikut:

\begin{tabular}{|l|c|c|}
\hline Atribut & $\begin{array}{l}\text { Klp. Kontrol (Pembela-jaran } \\
\text { Konvensional) }\end{array}$ & $\begin{array}{l}\text { Klp. Eksperimen (Pembela-ran } \\
\text { disertai integrasi Mathlet) }\end{array}$ \\
\hline Kelompok Atas & $\begin{array}{c}\text { Data Prestasi Belajar } \\
\text { Data Prestasi Belajar }\end{array}$ & Data Prestasi Belajar \\
\hline Kelompok Biasa & Data Prestasi Belajar \\
\hline
\end{tabular}

\section{Populasi dan Sampel}

Populasi dari penelitian ini adalah seluruh siswa Kelas VIII SMP di kota Singaraja. Ada 11 buah SMP Negeri dan Swasta di kota Singaraja. Dari sekolah sebanyak itu akan diambil 4 sekolah secara random sebagai sampel penelitian yang terdiri dari 3 SMP Negeri dan 1 SMP Swasta.

Randomisasi terhadap 7 SMP Negeri yang ada menghasilkan sampel SMPN 1, SMPN 5 dan SMPN 6. Sedangkan randomisasi terhadap 4 SMP Swasta menghasilkan SMP Bhaktyasa sebagai sampel penelitian. Dari SMP Negeri masingmasing diambil 4 kelas sebagai sampel, sedangkan dari SMP Bhaktyasa hanya diambil 2 kelas sebagai sampel. Secara keseluruhan penelitian ini melibatkan 421 orang, namun setelah dilakukan penyetaraan hanya tertinggal 240 orang siswa. Data dari 240 orang siswa inilah yang selanjutnya dianalisis untuk menjawab masalah dari penelitian ini.

\section{Instrumen Penelitian}

Instrumen utama yang digunakan dalam penelitian ini berupa tes prestasi belajar. Sebelum digunakan untuk mengambil data, tes tersebut terlebih dahulu divalidasi konstruknya oleh pakar dan guru bidang studi matematika. Kemudian juga divalidasi secara empirik melalui suatu uji coba.

Instrumen tambahan yang digunakan dalam penelitian ini berupa angket yang berisi pertanyaan tentang kesan-kesan guru dalam melaksanakan eksperimen, baik kesannya terhadap mathlet yang digunakan maupun kesannya terhadap proses belajar yang telah berlangsung.

\section{Analisis Data}

Data prestasi belajar yang diperoleh dalam penelitian ini akan dianalisis secara statistik. Adapun analisis statistik yang digunakan dalam penelitian ini secara ringkas adalah sebagai berikut: 


\begin{tabular}{|c|c|c|c|}
\hline${ }^{B}$ & $\begin{array}{l}\text { Pembelajaran dengan bantuan } \\
\text { Mathlet }\end{array}$ & Pem & \\
\hline $\begin{array}{ll}\text { Siswa } & \text { Klp. } \\
\text { Atas }\end{array}$ & $\begin{array}{l}\text { Data hasil belajar } \mathrm{X}_{\mathrm{i11}}, \sum_{\bar{i}} X_{\mathrm{i} 11}, \\
\bar{X}_{11}, \quad \sum_{i}\left(X_{i 11}-\bar{X}_{11}\right)^{2} \\
\overline{A B}_{11}\end{array}$ & $\begin{array}{l}\text { Data hasil belajar } X_{i 12,}, \sum_{i} X_{i 12 x} \\
\bar{X}_{12}, \quad \sum_{i}\left(X_{i 12}-\bar{X}_{12}\right)^{2} \\
\overline{A B}_{12}\end{array}$ & $\begin{array}{l}\sum_{k k} \sum_{i} X_{k 11 k^{\prime}} \\
\bar{X}_{1^{* j}} \hat{A}_{1}\end{array}$ \\
\hline $\begin{array}{l}\text { Siswa KIp. } \\
\text { Menengah }\end{array}$ & $\begin{array}{l}\text { Data hasil belajar } \mathrm{X}_{\mathrm{i} 21}, \sum_{i} X_{\mathrm{i} 21^{x}} \\
\bar{X}_{21}, \quad \sum_{i}\left(X_{i 21}-\bar{X}_{21}\right)^{2} \\
\bar{A}_{21}\end{array}$ & $\begin{array}{l}\text { Data hasil belajar } \mathrm{X}_{\text {i22 }}, \sum_{i} X_{i 22} \\
\bar{X}_{22}, \quad \sum_{i}\left(X_{i 22}-\bar{X}_{22}\right)^{2} \\
\bar{A} \bar{B}_{22}\end{array}$ & $\begin{array}{l}\sum_{k} \sum_{i} X_{n j 2 k}, \\
\bar{X}_{2}, \hat{A}_{2}\end{array}$ \\
\hline & $\sum_{j} \sum_{i} X_{i j 1} \quad, \quad \bar{X}_{01}, \hat{B}_{1}$ & $\sum_{j} \sum_{i} X_{i j 2}$ & 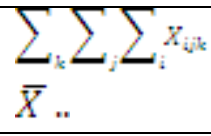 \\
\hline
\end{tabular}

Selanjutnya juga perlu dihitung harga-harga berikut:
a. $\mathrm{SS}_{\mathrm{A}}=\mathrm{nK} \sum_{j=1}^{J} A_{j}^{2}$
b. $\mathrm{SS}_{\mathrm{B}}=\mathrm{nJ} \sum_{k=1}^{K} B_{k}^{2}$
c. $\mathrm{SS}_{\mathrm{AB}}=\mathrm{SS}_{\mathrm{A}+\mathrm{B}+\mathrm{AB}}-\mathrm{SS}_{\mathrm{A}}-\mathrm{SS}_{\mathrm{B}}$
d. $\mathrm{SS}_{\mathrm{A}+\mathrm{B}+\mathrm{AB}}=\mathrm{n} \sum_{k} \sum_{j}\left(\bar{X}_{j k}-X_{\mathrm{e}}\right)^{2}$

e. $\quad S_{\mathrm{W}}=\sum_{k} \Sigma_{j} \sum_{i}\left(X_{i j k}-\overline{X_{m}}\right)^{2}$ dengan SS adalah singkatan dari jumlah kuadrat (Sum Of Square). Dari perhitunganperhitungan di atas akhirnya diperoleh nilainilai berikut ini yang selanjutnya digunakan menguji hipotesis dari penelitian ini.

\begin{tabular}{|l|c|c|c|c|}
\hline \multicolumn{1}{|c|}{ Sumber } & SS & $\begin{array}{c}\text { Derajat } \\
\text { kebebasan (v) }\end{array}$ & $\begin{array}{c}\text { MS (Mean of } \\
\text { square })\end{array}$ & F \\
\hline Faktor A & $\mathrm{SS}_{\mathrm{A}}$ & $\mathrm{K}-1$ & $\mathrm{SS}_{\mathrm{A}} /(\mathrm{K}-1)$ & $\mathrm{MS}_{\mathrm{A}} / \mathrm{MS}_{\mathrm{W}}$ \\
Faktor B & $\mathrm{SS}_{\mathrm{B}}$ & $\mathrm{J}-1$ & $\mathrm{SS}_{\mathrm{B}}(\mathrm{J}-1)$ & $\mathrm{MS}_{\mathrm{B}} / \mathrm{MS}_{\mathrm{W}}$ \\
Interaksi A $\mathrm{B}$ & $\mathrm{SS}_{\mathrm{AB}}$ & $(\mathrm{K}-1)(\mathrm{J}-1)$ & $\mathrm{SS}_{\mathrm{AB}} /((\mathrm{K}-1)(\mathrm{J}-1))$ & $\mathrm{MS}_{\mathrm{AxB}} / \mathrm{MS}_{\mathrm{W}}$ \\
Error & $\mathrm{SS}_{\mathrm{W}}$ & $\mathrm{JK}(\mathrm{n}-1)$ & $\mathrm{SS}_{\mathrm{W}} /(\mathrm{JK}(\mathrm{n}-1))$ & \\
\hline
\end{tabular}

Harga $F$ yang pertama dan kedua digunakan untuk menguji efek utama dari penelitian ini, sedangkan harga $F$ yang ketiga digunakan untuk menguji efek interaksi dalam penelitian ini. Taraf signifikansi yang digunakan dalam penelitian ini adalah $95 \%$.

\section{HASIL DAN PEMBAHASAN}

Data yang diperoleh dalam penelitian ini selanjutnya dianalisis dengan menggunakan software statistik MINITAB. Hasil dari analisis tersebut adalah sebagai berikut: 


\begin{tabular}{|lrrrrr}
\hline \multicolumn{7}{l}{ Two-way ANOVA: Prestasi versus Level, Mathlet } \\
Analysis of & Variance & for Prestasi & & \\
Source & DF & SS & MS & F & P \\
Level & 1 & 4918 & 4918 & 30.63 & 0.000 \\
Mathlet & 1 & 3747 & 3747 & 23.33 & 0.000 \\
Interaction & 1 & 210 & 210 & 1.31 & 0.254 \\
Error & 236 & 37893 & 161 & & \\
Total & 239 & 46767 & & & \\
\end{tabular}

Dari hasil analisis di atas dapat dikatakan bahwa integrasi mathlet ke dalam pembelajaran matematika memberikan pengaruh yang positif terhadap prestasi belajar. Demikian juga halnya dengan tingkat kemampuan siswa. Namun dari sudut interaksi, ternyata tidak terdapat interaksi antara integrasi mathlet dan tingkat kemampuan siswa terhadap prestasi belajar siswa. Dengan demikian, pengaruh positif integrasi mathlet terhadap prestasi belajar matematika bersifat umum, tidak bergantung pada tingkat kemampuan siswa.

Pengaruh positif tersebut memang sesuai dengan teori, karena integrasi mathlet ke dalam pembelajaran matematika benar-benar mampu meningkatkan keterlibatan siswa dalam pembelajaran. Hal ini disebabkan karena mathlet-mathlet tersebut dirancang agar eksploratif, menarik, dan bersifat problem solving. Sifat balikan yangsegera dalam pembelajaran berbantuan mathlet ini juga merupakan hal yang sangat membantu siswa dalam memahami konsep secara berkesinambungan.

Hal-hal positif dalam pembelajaran di atas bukan hanya opini, tetapi benar- benar terjadi di kelas. Hal ini terbukti dari tanggapan guru terhadap proses pembelajaran yang sudah dilakukan, yakni (i) bahwa siswa sangat termotivasi dalam belajar, (ii) bahwa diskusi di depan komputer benar-benar bersifat akademik, bukan ngobrol kesana-kemari, (iii) bahwa diskusi kelas pun bersifat sangat konstruktif. Bukan itu saja, malah ada guru yang melaporkan bahwa beberapa siswa kelas III protes mengapa mereka tidak dibelajarkan dengan bantuan mathlet tersebut.

\section{KESIMPULAN DAN SARAN}

Dari hasil yang telah diperoleh dalam penelitian ini dapat disimpulkan bahwa:

1. Pengintegrasian mathlet dalam pembelajaran matematika memberikan pengaruh positif terhadap prestasi belajar matematika siswa baik pada kelompok siswa yang pintar maupun pada kelompok siswa yang biasabiasa saja,

2. Tidak terdapat interaksi antara pengintegrasian mathlet dan tingkat 
kemampuan siswa terhadap prestasi belajar siswa.

Berdasarkan pada hasil penelitian yang telah dilakukan, peneliti juga menyarankan hal-hal berikut:

1. agar belajar membuat mathlet atau memodifikasi mathlet yang sudah ada untuk membantu siswa dalam belajar matematika,

2. guru sebaiknya menggunakan mathlet dalam pembelajaran matematika untuk meningkatkan kualitas pembelajarannya,

3. agar lebih menyadari bahwa pemanfaatan TIK dalam pembelajaran lebih dari sekedar penggunaan powerpoint yang kebanyakan sifatnya hanya tayangan dimana siswa tidak diberi kesempatan untuk melakukan eksplorasi terhadap konsep-konsep yang dipelajari.

\section{DAFTAR PUSTAKA}

Ahmad, Kamaludin, 2001. ICT \& Teori Pembelajaran (dari Learning to Teach Using ICT in the Second-ary School). http://users.ictp.it/ stevanof/ mylist.html diakses 15 April 2007.

Akour, Ahmed. 2005. The Effects of Computer-Assisted Instruction on Jordanian College Students', Electronic Journal for the Integra-tion of Technology in Education, Vol. 5. http://users.ictp.it/ stevanof/mylist. html diakses 23 Juni 2007.

Briggs, Mary and Alan Pritchard. 2005. Using ICT in Primary Mathematics Teaching. Exeter UK: learning Matters Ltd.

Collins, Janet, Michael Hamond, and Jerry Wellington.1997. Teaching and Learning with Multimedia. Great Britain: Routledge.

Cuoco, Albert A., E. Paul Goldenberg, and Jane Mark. 1995. Technolo-gy Tips.
Constructions and investigations with dynamic geometry software. Technology in Perspective. No. 87. pp. 450452

Depdiknas. 2004. Kurikulum 2004 Sekolah Menengah Pertama (SMP). Pedoman Khusus Pe-ngembangan Silabus Berbasis Kompetensi Mata Pelajaran Matematika. Jakarta: Direktorat Jenderal Pendidikan Dasar dan Menengah.

Gadanidis, George. 2000. The Effect of Interactive Applet in Mathematics Teaching. Faculty of Education, University of Western Ontario. Diakses 5 Nopember 2008.

Iskander, Magdy F. et.al. 2003. Interactive Multimedia Lessons for Education. CAEME Center College of Engineering University of Utah Salt Lake City, Utah 84112. http://tutorial.math.

lamar.edu/cheat table.aspx Diakses tgl. 8 Juni 2007.

Klotz, E.A. 1991. "Visualization in Geometry: A Case Study of Multimedia Mathematical Education Project." Dalam Walter Zimmerman and Steven Cunningham. Visualization in Teaching and Learning Mathematics. USA: The Mathematical Association of America.

Mulyanto, Agus, dkk. 2005. Matematika Untuk Kelas VIII SMP Jilid 2. Yogyakarta: PT Citra Aji Parama.

Polya, G. 1973. How to Solve It. Princeton University Press. New Jersey.

Schoenfeld, A. (Ed.). 1987. Cognitive Science and Mathematics Education. New Jersey: Lawrence Erlbaum Inc. Publisher.

Silverman, L.K. 1998. Guidelines for Teaching Visual-Spatial Learners (VSL). $\quad$ www.visualspatial.org Diakses tanggal 1 Desember 2006.

Sobel, Max A., and Evan M. Maletsky. 1999. Teaching mathematics: A Sourcebook of Aids, Activities and Strategies. USA: Allyn \& Bacon A Viacom Company. 
Suwarsono, 1998. Peranan Strategi Visual dalam Pembelajaran Mate- matika. Makalah disampaika pada Seminar Nasional "Pendidikan Matematika dalam Era Globali-sasi” yang diselenggarakan oleh Program Pasca Sarjana IKIP Malang 4 April 1998.

Suweken, Gede. 2007. Peningkatan Pemahaman dan Apresiasi Mahasiswa Terhadap Kalkulus II Melalui Visualisasi Berbantuan Komputer Pada Mahasiswa Jurusan Pendidikan Matematika Undiksha Singaraja. Undiksha: Laporan Teaching Grant P3AI

Suweken, Gede. 2007. Pembelajaran Berbantuan Excel dan Author-ware untuk Meningkatkan Pemahaman Konsep Fungsi Kuadrat Siswa SMA Kelas $X$. Undiksha: Laporan Penelitian Research for Community Development IMHERE.

Suweken, Gede. 2008. Penggunaan Microsoft Excel untuk Meningkat- kan Motivasi dan Pemahaman Konsep Matematika Siswa Kelas VIII SMPN 6 Singaraja Tahun 2008. Undiksha: Laporan Penelitian DIPA 2008.

Thiagarajan, S., D.S. Semmel, M.L. Semmel. 1974. Instructional Development for Training Teacher of Exceptional Children. Minnesota: Indiana University.

Took, James D. and Norma Henderson. 2001. Using Information Technology in Mathematics education. USA: The Haworth Press, Inc.
Whiteley, W. 2004. Visualization in Mathematics: Claims and Questions Towards a Research Programs. www.visualspatial.org

Diakses tanggal 1 Desember 2006. 